\title{
Comunicación

PRESENTACIÓN

\section{Comunicación y Sociedad, hija de la década perdida}

\author{
PABLO ARREDONDO RAMÍREZ1
}

Un cuarto de siglo es un lapso considerable, podría decirse extraordinario, para la existencia y continuidad de un proyecto de difusión y análisis académico, como ha sido la historia de Comunicación y Socie$d a d$. Concebida a la luz de un proyecto de investigación, en la provincia mexicana, con la formación del Centro de Estudios de la Información y la Comunicación en 1986, hoy en día transformado en Departamento de Estudios de la Comunicación Social de la Universidad de Guadalajara, esta revista no fue tal, sino hasta el cuarto y quinto número de su existencia, cuando de manera embrionaria buscó conjuntar los elementos de lo que tendría que considerarse una "publicación periódica con rigor académico".

Los primeros pasos de este proyecto editorial se dieron a través de tres estudios monográficos aportados por igual número de (entonces) jóvenes académicos: Francisco de Jesús Aceves con La televisión en Guadalajara: génesis y desarrollo; Guillermo Orozco Gómez, con Televisión y producción de significados (tres ensayos), y Enrique Sánchez Ruiz con Centralización, poder y comunicación en México, constituyeron los cimientos de este proyecto editorial. Desde aquellos días muchos cambios han operado tanto en el contexto que le dio origen a esta revista, como en los objetos de estudio en los que se ha concentrado a lo largo de 25 años.

1 Universidad de Guadalajara, México.

Correo electrónico: pablor@csh.udg.mx 
Comunicación y Sociedad vino al mundo en el tiempo en que los aires del llamado "neoliberalismo" arreciaban en todos los puntos cardinales del orbe. El Estado, en las sociedades avanzadas y a su manera en las menos desarrolladas, fue llevado al banquillo de los acusados, bajo la amenaza de comenzar el desmantelamiento de las políticas públicas que le habían dado forma desde la postguerra. Había llegado el tiempo de privilegiar al mercado, de apoyar las bondades de la presunta competencia y la desregulación en la economía. En las tierras latinoamericanas todavía se apreciaba el tufo de los regímenes autoritarios (de extracción militar en su mayoría), aunque un proceso tenue de liberalización política que abriría las puertas a esquemas de democracia electoral se había puesto en marcha. En escenarios como el mexicano, tras dos magnas crisis de naturaleza económica (en 1976 y 1982) se hacía evidente el desgaste de un modelo de control político sui generis, que estaba a punto de sufrir una de sus mayores pruebas con la escisión del partido que había mantenido, desde hacía más de cinco décadas, la hegemonía indiscutible en el sistema político nacional.

Mercado a la alza, privatizaciones en boga, relativa liberalización política y movimientos sociales de múltiple naturaleza marcaron un decenio que culminaría, entre otras situaciones inéditas, con el derrumbe del socialismo de la antigua Unión Soviética y con un proceso intenso de globalización del capitalismo triunfante. Una década a la que más de alguno, con justa razón, bautizó como la "década perdida", marcada por altos índices de inflación económica, deudas externas impagables y un significativo déficit fiscal en las cuentas públicas. Una etapa que exacerbó la multiplicación de la pobreza en prácticamente toda la América Latina y, muy particularmente, en México.

Tales dinámicas no fueron ajenas al mundo de la comunicación y al de su estudio. Si bien la revolución tecnológica de las comunicaciones fue más notable durante los años noventa y en los albores del nuevo milenio, las marcas estaban puestas desde los años del decenio perdido. Internet operaba de manera restringida en las comunidades de iniciados en Estados Unidos, pero ya iniciaba su explosión; las computadoras ya habían cambiado su escala para ser incorporadas como un electrodoméstico más en los hogares y un sustituto de diversas tecnologías de oficina; las redes telemáticas, si bien incipientes, estaban 
prefiguradas en el entorno empresarial más que en el social; la televisión por cable no era novedad, pero su popularización desde luego que sí, tanto como la multiplicación de los canales. Las llamativas antenas satelitales irrumpieron en los suburbios de las clases pudientes y experimentos audiovisuales como el llamado multipoint service fueron igualmente abrazados por los segmentos de una audiencia urbana más sofisticada y demandante. Y la interactividad mediática, podría decirse, era una pulsión en espera de ser realizada. Ese Big Bang sucedería pocos años más tarde.

Las "nuevas tecnologías" de entonces luchaban por un lugar en el océano del ecosistema comunicativo predominante, particularmente del subordinado a la televisión tradicional. El mismo medio que incluso en nuestros días establece las agendas y los derroteros de cuanta actividad social le apetece. Las viejas antenas han desaparecido poco a poco del paisaje urbano, pero el septuagenario medio está más metido que nunca en los hogares, en la vida cotidiana, en la economía y en la política. Así pues, la multiplicación de soportes, de mensajes y de audiencias ya estaba en marcha ascendente desde aquellos "ochenteros" días, como también lo estaba el crecimiento de la comunicología como disciplina en el territorio latinoamericano.

Sin duda, un fenómeno incuestionable del interés creciente por los procesos comunicativos en aquella década, en el ámbito de América Latina, se manifestó en la intensa creación de escuelas y facultades de comunicación. México no fue ajeno a ello. En apenas unos cuantos años, el número de instituciones dedicadas a la formación de profesionistas para la comunicación alcanzó proporciones considerables y su explosiva dinámica se tornó, simultáneamente, en objeto de estudio para más de un académico de la propia disciplina. Aunque de manera más modesta, la multiplicación de escuelas y facultades de comunicación abrió la puerta a un interés por abordar - desde la investigaciónlos fenómenos comunicativos, tanto aquellos que se circunscribían de manera directa al mundo de los medios como los que tenían que ver con las llamadas mediaciones socioculturales.

Frente a las corrientes anglosajonas de la Communication Research (más criticadas que comprendidas), y aquellas inspiradas en el marxismo (muy populares durante los años setenta), ciertos académicos lati- 
noamericanos estaban empeñados en desarrollar los paradigmas teóricos que explicarán nuestra realidad y preocupaciones desde una óptica más próxima a las manifestaciones culturales y sociales de la región. Nuestra propia versión de los cultural studies emergió como modelo conceptual, centrado menos en las manifestaciones tecnológicas y más en las dinámicas complejas de una sociedad distinguida por la polarización de todo cuño y por las especificidades de una cultura mestiza.

Con todo, la preocupación inherente al papel económico de la industria mediática, en tanto industria cultural, y la complicidad de los grandes medios con los esquemas imperantes de dominación política, bastante ajenos a la democracia, no dejaron de estar presentes en la agenda de los investigadores de la comunicación de esos años. En nuestro país, ello se reflejó en un intento por mantener viva la discusión pública sobre la necesidad de reglamentar y, por tanto, hacer efectivo el derecho a la información; un logro de naturaleza constitucional obtenido al finalizar la década anterior, pero inconcluso. Un "triunfo" que formó parte de una reforma política que abrió las puertas de la participación electoral a fuerzas que hasta entonces habían sido consideradas al margen de la ley. Fueron los primeros síntomas de un proceso de agotamiento del sistema autoritario mexicano.

Paralelamente, la creciente concentración de los esquemas corporativos imperantes en el sector de los medios, muy especialmente en la radio y la televisión, y la pálida participación del Estado en este territorio, por no hablar de la titubeante política pública en la materia, plagaron la agenda de preocupaciones de los escasos núcleos de investigación que para entonces operaban en el país.

De hecho, Comunicación y Sociedad nació en el contexto de un esfuerzo por cimentar un proyecto de investigación, más o menos riguroso, fuera de los espacios centralizados y centralistas que para entonces dominaban la mayor parte de la actividad académica en el campo de la comunicación. Se trataba de un proyecto universitario encaminado a generar conocimiento y reflexión en lo que ya se prefiguraba como el estratégico territorio de la comunicación mediada y de la cultura.

Así pues, el lector tiene en sus manos una publicación cuya gestación fue producto de un esfuerzo académico de mayor talante; de un espacio con fines de formación de recursos humanos y de generación 
de conocimiento socialmente pertinente que, a lo largo de estos años, se ha empeñado en convocar la diversidad obligada para el entendimiento de los complejos fenómenos que aborda.

Los escenarios contemporáneos relativos a la comunicación, si bien anclados en su pasado inmediato, han sufrido transformaciones incuestionables. La abrumadora revolución de las tecnologías de la información y de la comunicación está impactando, de forma y de fondo prácticamente a todas las áreas de la actividad humana. La mediatización social se extiende tanto a los terrenos de la lucha y preservación del poder político, como a los centros neurálgicos de la economía, por no hablar de la cotidianidad simbólica de miles de millones de seres humanos. Revolución tecnológica y dilemas tradicionales como la identidad y el sentido de pertenencia, se diluyen en dinámicas únicas. Situaciones que, hasta no mucho, eran imaginadas como parte de una ficción tecno-social posible son ahora práctica cotidiana. La "aldea global" pasó de ser una metáfora a convertirse en una realidad.

Entre los polos que recorren lo últimos 25 años, la revista Comunicación y Sociedad ha debido desarrollarse, no sin pocas dificultades. Dos épocas y 58 números después (40 de la primera época y 18 de la actual) la publicación de marras sobrevive con los signos de la vitalidad y la diversidad que la vieron nacer. Se ha constituido en un territorio de temáticas variadas que abordan -desde ópticas diversas, en ocasiones antagónicas- un plural número de objetos de estudio: el desarrollo e impacto social de los medios "tradicionales", la conformación y desenvolvimiento de las audiencias de toda índole, el análisis de las políticas públicas, la economía política de la comunicación, la vinculación religiosidad y cultura, las apropiaciones simbólicas, el análisis de flujos informativos, los estudios sobre el periodismo, el desarrollo cinematográfico, las culturas juveniles, el análisis sobre el devenir de la comunicación como campo académico, los estudios regionales, los estudios de la realidad comunicacional latinoamericana, el análisis crítico de la mercadotecnia, las expresiones comunicativas de los pueblos indígenas, los debates teóricos y metodológicos, etc. Una miríada de intereses y de objetos de estudio pertenecientes al complejo y basto universo de la comunicación han transitado por las páginas de esta publicación diversa, plural y crítica desde los años ochenta. 
Y precisamente en este número, el de su vigésimo quinto aniversario, Comunicación y Sociedad busca reafirmar su vocación inicial y la madurez académica adquirida a lo largo de estos años. El lector tiene en su manos -en los ensayos de investigación contenidos en este ejemplar- una muestra palpable de la naturaleza académica de una iniciativa universitaria que hace un cuarto de siglo arrancó con el ánimo y las pretensiones que hoy confirma. 